\title{
ESTRATÉGIA DE MANEJO DE Tibraca limbativentris Stål. (HEMIPTERA: PENTATOMIDAE) NA ENTRESSAFRA DA CULTURA DO ARROZ IRRIGADO
}

\author{
Robson Antonio Botta ${ }^{1}$, Fernando Felisberto da Silva ${ }^{1}$, Juliano de Bastos Pazini ${ }^{1}$, Rodrigo \\ Rubenich $^{1}$ \\ ${ }^{1}$ Universidade Federal do Pampa (UNIPAMPA), E-mail: robson_a.b@hotmail.com, \\ fernando.silva@unipampa.edu.br, julianopazzini@ hotmail.com, rodrigorubenich@ hotmail.com
}

\section{RESUMO}

Este artigo avalia a interação e a eficiência dos controles mecânico e químico como estratégia de manejo para reduzir as populações de Tibraca limbativentris em sítios de hibernação, em Itaqui, estado do Rio Grande do Sul, Brasil. A prática da roçada + tiametoxicam reduziu a população de $T$. limbativentris quando utilizada na vegetação de bordadura da lavoura de arroz irrigado mostrando ser uma estratégia eficiente para o manejo da praga na entressafra da cultura.

Palavras-chave: Tibraca limbativentris, população hibernante, controle mecânico, controle químico

\section{MANAGEMENT STRATEGY OF Tibraca limbativentris Stål. (HEMIPTERA: PENTATOMIDAE)IN THE OFFSEASON OF IRRIGATED RICE CROP}

\begin{abstract}
This paper evaluates the interaction and the efficiency of mechanical and chemical controls as a management strategy to reduce the Tibraca limbativentris, populations at the hibernation sites, in Itaqui, state of Rio Grande do Sul, Brazil. The treatment interacting mowing + thiamethoxam provided the reduction of $T$. limbativentris population when used in the border vegetation of irrigated rice crop, thus showing to be an efficient strategy for the pest management in the offseason of the crop.
\end{abstract}

Keywords: Tibraca limbativentris, hibernating population, mechanical control, chemical control

\section{INTRODUÇÃO}

O estado do Rio Grande do Sul é o maior produtor de arroz (Oryza sativa L.), irrigado do Brasil. Afetando o desenvolvimento e a produtividade das lavouras de arroz destacam-se as doenças e os insetos (GOMES \& MAGALHÃES JÙNIOR, 2004). Uma das pragas-chaves da cultura é o percevejo Tibraca limbativentris Stål., 1860 (Hemiptera: Pentatomidae), também conhecido como percevejo-docolmo do arroz (MARTINS et al., 2004).

$\mathrm{O}$ inseto preferencialmente se estabelece em plantas situadas em pontos não atingidos pela lâmina de água. Por esse motivo, sua incidência é maior nas lavouras implantadas em terrenos inclinados, predominantes no Planalto da Campanha do Rio Grande do Sul. Nesse tipo de lavoura, há maior proximidade das taipas, sobre as quais o arroz também é semeado, proporcionando 


\section{ESTRATÉGIA DE MANEJO DE Tibraca limbativentris Stål. (HEMIPTERA: PENTATOMIDAE) NA ENTRESSAFRA DA CULTURA DO ARROZ IRRIGADO}

maior população de plantas em condições favoráveis ao inseto (MARTINS et al., 2009).

Em função de variações fotoperiódicas e disponibilidade de alimentos, principalmente em zonas temperadas, os adultos de $T$. limbativentris podem desenvolver hábito hibernante, passando por um período de diapausa durante a entressafra refugiados em sítios de hibernação, como plantas que se desenvolvem marginalmente à lavoura (LINK et al., 1996).

O maior problema associado ao percevejo-do-colmo é o fato do controle ser efetuado por meio de inseticidas químicos, sem considerar princípios do manejo integrado de pragas. Em grandes lavouras as aplicações têm sido efetuadas, basicamente, por via aérea, antecipadamente à época indicada, sem o monitoramento de populações, usando inseticidas sem registro. Ademais, as pulverizações atingem, principalmente, adultos no topo das plantas de arroz, mas não atingem grande quantidade de ninfas, responsáveis por iguais danos, que permanecem protegidas entre os colmos, na base dessas plantas (MARTINS et al., 2009).

Nesse sentido, torna-se necessário a adoção de práticas culturais diversificadas, sejam elas químicas, biológicas ou mecânicas que possibilitem diminuir $\mathrm{o}$ desenvolvimento populacional do percevejodo-colmo. Para isso, deve-se conhecer os hábitos e os locais onde os insetos se encontram durante o ano. Munidos dessas informações os produtores terão subsídios suficientes para adotar o manejo adequado.

Dentre essas práticas de controle que poderiam ser implementadas, destacam-se a destruição de plantas hospedeiras localizadas em torno da lavoura e de qualquer elemento que venha servir de abrigo aos insetos no período da entressafra (PAZINI et al., 2012). $\mathrm{O}$ monitoramento de áreas adjacentes às lavouras de arroz, durante a entressafra, é de suma importância, pois, por hipótese, se for verificada a presença do inseto-praga nestes locais, poderiam ser adotadas estratégias que promovam a redução da população hibernante do percevejo-do-colmo e, consequentemente, as infestações na safra seguinte.

Neste contexto, o objetivo deste trabalho foi avaliar a interação e a eficiência dos controles mecânico e químico na redução populacional de $T$. limbativentris Stål. (Hemiptera: Pentatomidae) em sítio de hibernação.

\section{MATERIAL E MÉTODOS}

O experimento foi implantado em sítio de hibernação de $T$. limbativentris, no período de entressafra, nos anos agrícolas 2011/12 e 2012/13, às margens de lavoura de arroz irrigado, na Granja "D'Mata" localizada no município de Itaqui, RS $\left(29^{\circ} 07^{\prime} 30^{\prime \prime} S\right.$ e $\left.56^{\circ} 33^{\prime} 10^{\prime \prime O}\right)$. A vegetação predominante no local era rabo-de-burro (Adropogon sp.) e capim-annoni (Eragrostis plana). Foram testados seis tratamentos, que contaram com dois métodos de controle mecânico e químico e, ainda, a interação entre ambos (Tabela 1) e um tratamento controle, sem aplicação de inseticida ou realização de roçada.

O delineamento experimental foi inteiramente casualizado, com quatro repetições, abrangendo uma área de 3 x $5 \mathrm{~m}$ por parcela, espaçadas $2 \mathrm{~m}$ entre si com o objetivo de evitar a deriva entre os tratamentos.

Em cada unidade experimental foi lançado um quadro de metal medindo 0,25 $\mathrm{m}^{2}$, para auxiliar na amostragem visual dos insetos presentes na vegetação. Este procedimento repetiu-se aleatoriamente em três pontos para cada parcela na intenção de verificar a população média de percevejodo-colmo hibernante. 
Tabela 1. Tratamentos utilizados para o controle de Tibraca limbativentris em sítio de hibernação nas entressafras de 2011/12 e 2012/13, Granja D’Mata, Itaqui, RS.

\begin{tabular}{|c|c|c|c|}
\hline Tratamentos & Marca Comercial & $\begin{array}{c}\text { Concentração do } \\
\text { i.a.* }\end{array}$ & Dose do p.c.** \\
\hline roçada & -- & -- & -- \\
\hline tiametoxam & Actara ${ }^{\circledR} 250 \mathrm{WG}$ & $250 \mathrm{~g} \cdot \mathrm{L}^{-1}$ & 125 g.ha ${ }^{-1}$ \\
\hline lambda-cialotrina & Karate Zeon® 50 CS & 50 g. $\mathrm{L}^{-1}$ & 150 mL.ha ${ }^{-1}$ \\
\hline roçada + tiametoxam & & --+250 g. $\mathrm{L}^{-1}$ & --+125 g.ha ${ }^{-1}$ \\
\hline roçada + lambda-cialotrina & & --+50 g... ${ }^{-1}$ & $--+150 \mathrm{~mL} \cdot \mathrm{ha}^{-1}$ \\
\hline
\end{tabular}

*(i.a.) ingrediente ativo; **(p.c.) produto comercial.

Antecipadamente a aplicação dos tratamentos avaliou-se a ocorrência natural do percevejo-do-colmo, por meio de uma pré-contagem. Após, realizou-se a roçada nas parcelas correspondentes, deixando a vegetação numa altura entre 5 a 7 centímetros do solo.

A aplicação dos demais tratamentos foi feita com o auxílio de pulverizador costal pressurizado a $\mathrm{CO}_{2}$ equipado com uma barra de quatro pontas de pulverização (marca Teejet), com jato num ângulo de $110^{\circ} \mathrm{e}$ pressão de 0,2 gal.min $^{-1}$ numa pressão de trabalho de 40 PSI, usando a vazão de 150 L.ha ${ }^{-1}$, imediatamente após a roçada. Após as aplicações dos tratamentos, foram realizadas cinco amostragens aos 2, 4, 6, 10 e 15 dias após a aplicação (DAA) para verificação da eficiência de controle.

Os dados foram submetidos a análise de variância (ANOVA), sendo, na presença de significância pela estatística $\mathrm{F}$, as médias comparadas pelo teste de Tukey a $5 \%$ de probabilidade $(\mathrm{p} \leq 0,05)$. A avaliação da eficiência de controle ou mortalidade foi corrigida pela fórmula de Henderson e Tilton (HENDERSON \& TILTON, 1955), sendo as mesmas comparadas entre os anos através do teste do qui-quadrado.

\section{RESULTADOS E DISCUSSÃO}

Os resultados obtidos evidenciaram que o número médio de percevejos por metro quadrado, na pré-contagem, foi aproximado em todos os tratamentos ( $\mathrm{F}=1,6134 ; \mathrm{p}=0,1814 ; \mathrm{CV}=25,1 \%)$, o que satisfaz a condição ideal para que os tratamentos fossem aplicados em igualdade de condições. Verificou-se, ainda, uma diferença entre os anos, tratamentos, DAA e uma interação dos tratamentos em função dos anos em que o experimento foi conduzido e DAA (Tabela 2).

Todos os tratamentos reduziram significativamente o número médio de percevejos-do-colmo no sítio de hibernação, destacando-se os tratamentos com roçada + tiametoxam, tiametoxam e roçada com as menores médias (Tabela 3).

Pela análise dos dados observa-se que quanto maior o período após a aplicação da roçada+tiametoxam maior foi a mortalidade, com exceção do tratamento apenas com tiametoxam, que apresentou ligeira elevação no número de insetos aos 15 DAA. Os tratamentos que tiveram a associação do inseticida químico mais a roçada foram os que mais mantiveram a estabilidade, ou seja, não apresentaram variações populacionais significativas durante o período de amostragem, mantendo a população em baixo nível ao longo do tempo (Tabela 4). Tal fato justifica-se devido a roçada eliminar a vegetação mais abundante, provocar a movimentação dos 


\section{ESTRATÉGIA DE MANEJO DE Tibraca limbativentris Stål. (HEMIPTERA: PENTATOMIDAE) NA ENTRESSAFRA DA CULTURA DO ARROZ IRRIGADO}

insetos e expor as regiões de crescimento das plantas para a absorção dos inseticidas.

Verificou-se que no tratamento com roçada + lambda-cialotrina, ocorreu um efeito de choque ocasionando um rápido decréscimo na população. Este efeito é típico dos inseticidas piretroides e ação de contato (RIGITANO \& CARVALHO, 2001; SANTOS et. al., 2007), que pode ter tido efeito adicional pelo impacto inicial da roçada, que provocou a movimentação dos insetos sobre a superfície aplicada com inseticida. No entanto, os insetos ao movimentarem-se vagarosamente, visto estarem em hibernação, fugiram do local ou migraram depois do efeito residual ou degradação da molécula, por volta de 7 a 10 DAA, fato que provocou dificuldade de controle neste tratamento nas avaliações após os 6 DAA.

No tratamento com roçada + tiametoxam a população decresceu potencialmente ao longo do tempo, mantendo boa eficiência, a qual atingiu $100 \%$ no segundo ano de estudo (Tabela 5). Sob o ponto de vista fisiológico nas plantas, a roçada, estimulando o surgimento de novas brotações, bem como expondo as partes verdes das gramíneas, pode ter auxiliado na absorção do tiametoxam.

Também, em gramíneas, conforme se aumenta a altura do dossel, ocorre diminuição na densidade da massa seca de lâminas foliares verdes (SILVA et al., 2007), ou seja, a roçada pode aumentar a área de absorção dos inseticidas uma vez que estimula brotações de folhas com maior massa e expõe a região de crescimento.

Em relação a eficiência de controle, tendo em vista a baixa precipitação no ano de 2011, os tratamentos obtiveram baixa eficiência quando comparados aos de 2012, provavelmente dificultando o desempenho das moléculas de inseticidas no que se refere à absorção, translocação e degradação. Apesar desta constatação, verificou-se que a eficiência de controle do tratamento roçada + tiametoxam foi o mais constante entre os anos de 2011 e 2012, não apresentando diferença entre ambos pelo teste do quiquadrado (Tabela 5).

Tabela 2. Resumo da análise de variância do número de Tibraca limbativentris, utilizando-se os dados obtidos nos tratamentos e dias após a sua aplicação nas entressafras dos anos de 2011/12 e 2012/13, Granja D’Mata, Itaqui, RS.

\begin{tabular}{lcc}
\hline Causas da Variação & GL & $\mathrm{F}^{1}$ \\
\hline Anos (A) & 1 & $107,7654 * *$ \\
Tratamentos (T) & 5 & $17,8075^{* *}$ \\
Dias Após a Aplicação (DAA) & 4 & $37,2981 * *$ \\
A x T & 5 & $3,9162^{* *}$ \\
A x DAA & 4 & $1,8025^{\mathrm{ns}}$ \\
T x DAA & 20 & $1,5819^{*}$ \\
A x T x DAA & 20 & $1,0612^{\mathrm{ns}}$ \\
\hline Tratamentos & 71 & $6,7319 * *$
\end{tabular}

\footnotetext{
${ }^{1}$ significativo ao nível de $5 \%(* *)$ e $1 \%(*)$ de probabilidade; ns: não significativo.
} 
Tabela 3. Número médio de percevejos-do-colmo nos tratamentos durante as entressafras de 2011/12 e 2012/13, Granja D’Mata, Itaqui, RS.

\begin{tabular}{|c|c|c|c|c|c|c|c|}
\hline \multirow{2}{*}{ Anos } & \multicolumn{6}{|c|}{ Tratamentos* } & \multirow{2}{*}{$\begin{array}{c}\text { Média } \\
\text { Geral }\end{array}$} \\
\hline & 1 & 2 & 3 & 4 & 5 & 6 & \\
\hline 2011 & $1,58 \mathrm{abA}$ & $1,26 \mathrm{bcA}$ & $1,60 \mathrm{abA}$ & $0,89 \mathrm{cA}$ & 1,42 abcA & $1,96 \mathrm{aA}$ & $1,45 \mathrm{~A}$ \\
\hline 2012 & $0,56 \mathrm{bB}$ & $0,73 \mathrm{bB}$ & $0,49 \mathrm{bB}$ & $0,38 \mathrm{bB}$ & $0,46 \mathrm{bB}$ & $1,88 \mathrm{aA}$ & $0,75 \mathrm{~B}$ \\
\hline $\begin{array}{l}\text { Média } \\
\text { Geral }\end{array}$ & $1,07 \mathrm{~b}$ & $0,99 \mathrm{bc}$ & $1,05 \mathrm{~b}$ & $0,63 \mathrm{bc}$ & $0,93 \mathrm{bc}$ & $1,92 \mathrm{a}$ & -- \\
\hline $\mathrm{CV} \%$ & & & & 55,13 & & & \\
\hline
\end{tabular}

*(1) lambda-cialotrina; (2) roçada; (3) roçada + lambda-cialotrina; (4) roçada + tiametoxam; (5) tiametoxam e (6) testemunha. Dados transformados em $x^{1 / 2}$. As médias seguidas pela mesma letra maiúscula na coluna e minúscula na linha não diferem pelo teste de Tukey a $5 \%$ de probabilidade $(p \leq 0,05)$.

Tabela 4. Número médio de percevejos por metro quadrado em cada tratamento (mecânico e químico) em função dos dias após a aplicação durante as entressafras de 2011/12 e 2012/13, Granja D’Mata, Itaqui, RS.

\begin{tabular}{lccccccc}
\hline \multirow{2}{*}{ DAA } & Média & \multicolumn{7}{c}{ Tratamentos } \\
\cline { 3 - 8 } & geral** & $1 * * *$ & 2 & 3 & 4 & 5 & 6 \\
\hline 0 & $2,33 \mathrm{~A}$ & $2,38 \mathrm{aA}$ & $1,82 \mathrm{aA}$ & $2,25 \mathrm{aA}$ & $2,55 \mathrm{aA}$ & $2,47 \mathrm{aA}$ & $2,50 \mathrm{aA}$ \\
2 & $1,36 \mathrm{~A}$ & $1,12 \mathrm{bB}$ & $1,31 \mathrm{bAB}$ & $1,05 \mathrm{bB}$ & $0,94 \mathrm{bB}$ & $1,45 \mathrm{abB}$ & $2.27 \mathrm{aAB}$ \\
4 & $1,17 \mathrm{AB}$ & $1,21 \mathrm{bB}$ & $0,71 \mathrm{bB}$ & $1,14 \mathrm{bB}$ & $0,55 \mathrm{bB}$ & $1,14 \mathrm{bBC}$ & $2,29 \mathrm{aAB}$ \\
6 & $1,16 \mathrm{AB}$ & $1,24 \mathrm{aB}$ & $1,18 \mathrm{aAB}$ & $1,32 \mathrm{aB}$ & $0,66 \mathrm{aB}$ & $1,03 \mathrm{aBC}$ & $1,53 \mathrm{aB}$ \\
10 & $0,85 \mathrm{~B}$ & $0,64 \mathrm{bB}$ & $0,59 \mathrm{bB}$ & $1,09 \mathrm{abB}$ & $0,54 \mathrm{bB}$ & $0,56 \mathrm{bC}$ & $1,66 \mathrm{aAB}$ \\
15 & $0,95 \mathrm{~B}$ & $0,74 \mathrm{bB}$ & $0,88 \mathrm{bB}$ & $0,73 \mathrm{bB}$ & $0,48 \mathrm{bB}$ & $1,04 \mathrm{abBC}$ & $1,81 \mathrm{aAB}$ \\
\hline
\end{tabular}

*Dias Após a Aplicação. **Dados transformados em $x^{1 / 2}$. ***Tratamentos: (1) lambda-cialotrina; (2) roçada; (3) roçada + lambda-cialotrina; (4) roçada + tiametoxam; (5) tiametoxam e (6) testemunha. As médias seguidas pela mesma letra maiúscula na coluna e minúscula na linha não diferem pelo teste de Tukey a $5 \%$ de probabilidade $(p \leq$ $0,05)$.

Tabela 5. Eficiência de controle (\%) segundo Henderson \& Tilton para Tibraca limbativentris por meio de métodos mecânico e químico nas entressafras de 2011/12 e 2012/13, Granja D’Mata, Itaqui, RS.

\begin{tabular}{|c|c|c|c|c|c|c|c|c|c|c|}
\hline \multirow{3}{*}{ DAA* } & \multicolumn{10}{|c|}{ Anos / Tratamentos } \\
\hline & 2011 & 2012 & 2011 & 2012 & 2011 & 2012 & 2011 & 2012 & 2011 & 2012 \\
\hline & \multicolumn{2}{|c|}{$1 * *$} & \multicolumn{2}{|c|}{2} & \multicolumn{2}{|c|}{3} & \multicolumn{2}{|c|}{4} & \multicolumn{2}{|c|}{5} \\
\hline 2 & 70,8 & 62,1 & 73,6 & 48,5 & 38,7 & 77,0 & 76,2 & 87,2 & 28,3 & 57,2 \\
\hline 4 & 53,4 & 80,7 & 61,4 & 52,8 & 51,9 & 88,3 & 84,7 & 100 & 79,7 & 45,2 \\
\hline 6 & 0,0 & 40,1 & 0,0 & 59,6 & 0,0 & 83,4 & 46,7 & 78,3 & 0,0 & 81,6 \\
\hline 10 & 0,0 & 79,7 & 25,5 & 84,4 & 21,2 & 100 & 86,6 & 83,9 & 16,9 & 86,3 \\
\hline 15 & 47,4 & 90,4 & 48,3 & 81,4 & 28,8 & 82,5 & 77,9 & 94,3 & 0,0 & 90,4 \\
\hline Média & 34,3 & 70,6 & 41,8 & 65,3 & 28,1 & 86,2 & 74,4 & 88,7 & 25,0 & 72,1 \\
\hline$\chi^{2}$ & \multicolumn{2}{|c|}{130,322} & \multicolumn{2}{|c|}{83,452} & \multicolumn{2}{|c|}{47,230} & \multicolumn{2}{|c|}{5,3330} & \multicolumn{2}{|c|}{161,409} \\
\hline$p$ & \multicolumn{2}{|c|}{$<0,0001$} & \multicolumn{2}{|c|}{$<0,0001$} & \multicolumn{2}{|c|}{$<0,0001$} & \multicolumn{2}{|c|}{0,2548} & \multicolumn{2}{|c|}{$<0,0001$} \\
\hline
\end{tabular}

*DAA: dias após o tratamento; **Tratamentos: (1) lambda-cialotrina; (2) roçada; (3) roçada + lambda-cialotrina; (4) roçada + tiametoxam e (5) tiametoxam. 


\section{ESTRATÉGIA DE MANEJO DE Tibraca limbativentris Stål. (HEMIPTERA: PENTATOMIDAE) NA ENTRESSAFRA DA CULTURA DO ARROZ IRRIGADO}

Este fato indica não ter havido influências ambientais sobre este tratamento, em função dos anos de estudo. Salienta-se ainda que a roçada foi o tratamento que apresentou a melhor eficiência, excetuandose sua associação com o tiametoxam, na situação de estiagem.

Neste sentido, Torres \& Rigitano (2012) colocam que inseticidas translocáveis via floema, embora raros, são bastante interessantes, pois poderiam ser utilizados em menor número de pulverizações para o controle de pragas que atacam folhas novas, que, ao serem emitidas, receberiam os compostos das folhas mais velhas. $\mathrm{O}$ tiametoxam é um destes inseticidas utilizado em doses relativamente baixas, sendo altamente sistêmico, devido a sua alta solubilidade em água (4.100 mg. $\mathrm{L}^{-1}$ a $\left.25^{\circ} \mathrm{C}\right)$ e ao seu baixo coeficiente de partição octanol/água (log Kow de - 0,13 em pH de 6,8), características pouco comuns em inseticidas e comuns em herbicidas. Cabe observar que quanto mais alta for a solubilidade e mais baixo for o coeficiente de partição, mais sistêmico será o produto (NOVARTIS, 1998; ANTUNES-KENYON \& KENNEDY, 2001).

$\mathrm{Na}$ formulação para aplicação no solo ou pulverização foliar o transporte do ingrediente ativo é acropetal (via xilema) e ocorre rapidamente após a aplicação, distribuindo-se por toda a planta a partir do local de aplicação e acumulando-se nas pontas das folhas, além de uma pequena quantidade do produto ser transportada via floema (basipetal). O produto formulado degrada-se rapidamente nas superfícies tratadas e a ação do composto pode ocorrer por contato e ingestão. Aplicado ao solo em esguicho dirigido ao colo da planta ou em superfície total, o composto é rapidamente absorvido pelas raízes, translocando-se para as diversas partes da planta, sendo que o produto exibe atividade sistêmica também quando aplicado sobre o caule ou tronco de plantas. Na formulação para o tratamento de sementes, o transporte do ingrediente ativo ocorre na direção acropetal, logo após o plantio e a emergência das plântulas, distribuindo-se por toda a planta e acumulando-se nas pontas das folhas, agindo nos insetos por ação de ingestão (NOVARTIS, 1998).

Apesar de geralmente o tiametoxam ser aplicado no solo ou dirigido ao colo (TEIXEIRA et al., 2002), devido a rápida translocação via xilema, em estudos com mamoneira constatou-se a translocação do tiametoxam tanto no xilema como no floema se redistribuindo pela planta, quando aplicado via foliar (TORRES \& RIGITANO, 2012), demonstrando que insetos sugadores de seiva elaborada podem ser controlados pelo inseticida mesmo aplicado nas folhas, o que sugere um controle para Tibraca limbativentris. $\mathrm{O}$ fator limitante para a eficiência e translocação do tiametoxam quando aplicado nas folhas seria o fato de ser um produto pouco estável quando exposto a luz, o que necessitaria de uma rápida absorção, antes que o mesmo fosse fotodesestabilizado.

Ao contrário do tiametoxam, a lambda-cialotrina é uma substância essencialmente insolúvel em água $(0,005$ mg. $\mathrm{L}^{-1}$ a $\left.25^{\circ} \mathrm{C}\right)$, com elevado coeficiente log Kow $(6,90$; em pH 7,0), ou seja, nãosistêmica e com atuação nos insetos por contato ou ingestão. Além disso, há evidências de rápida fotodegradação tanto em solo, água ou superfícies expostas à radiação solar (NOVARTIS, 1998).

Assim, a menor eficiência do controle mecânico em comparação ao controle químico sobre a população hibernante de $T$. limbativentris não permite classificá-lo como inutilizável, uma vez que esse método possui menor custo de aplicação e favorece a limpeza das áreas adjacentes às lavouras, reduzindo possíveis hospedeiros de outros insetos-praga, como também de doenças. 
Para maior eficácia da estratégia, os dados sugerem que a roçada seja aplicada quando os insetos estiverem estabilizados no sitio de hibernação e não logo após a colheita, pois, neste caso, isso acabaria com o fator refúgio, obrigando os insetos a buscarem abrigo em áreas mais distantes da borda. A manutenção desta vegetação na borda da lavoura logo após a colheita representaria uma "armadilha", concentrando altas populações do inseto. Após todos os insetos saírem da lavoura, ao término da colheita, seria indicado o controle mecânico, podendo este ser integrado à pulverização de um inseticida sistêmico. Aplicações deste mesmo inseticida sem a realização da roçada também não seriam eficientes, uma vez que a grande vegetação impede que os insetos sejam atingidos, bem como, pelo fato dela já estar em senescência, não haver a devida translocação do produto.

\section{CONCLUSÃO}

A prática da roçada + tiametoxam proporcionou a redução populacional de Tibraca limbativentris quando utilizado na vegetação de bordadura da lavoura de arroz irrigado, constituindo-se em uma estratégia eficiente de manejo da praga na entressafra do arroz irrigado.

\section{REFERÊNCIAS BIBLIOGRÁFICAS}

ANTUNES-KENYON, S.E.; KENNEDY, G. 2001. Tiametoxam: a new active ingredient review. Massachussetts, Pesticide Bureau. 37 p.

GOMES, A. S.; MAGALHÃES JÚNIOR, A. M. (Eds.). 2004. Arroz irrigado no Sul do Brasil. Pelotas: Embrapa Clima Temperado. 899p.

HENDERSON, C. F.; TILTON, E. W. 1955.

Tests with acaricides against the brow wheat mite. Journal of Economic Entomology, Geneva, v.48, n.2, p.157161.
LINK, D.; NAIBO, J.G.; PELENTIR, J.P. 1996. Hibernation sites of the rice stalk stink bug Tibraca limbativentris in the central region of Rio Grande do Sul, Brazil. International Rice Research Notes, Philippines, v.21, p.78.

MARTINS, J.F.S; BOTTON, M.; CARBONARI, J.J.; QUINTELA, E,D. 2004. Eficiência de Metarhizium anisopliae no controle do percevejo-docolmo Tibraca limbativentris (Heteroptera: Pentatomidae) em lavoura de arroz irrigado. Ciência Rural, Santa Maria, v.34, n.6, p.1681-1688.

MARTINS, J.F.S.; BARRIGOSSI, J.A,F.; OLIVEIRA, J.V.; CUNHA, U.S. 2009. Situação do manejo integrado de insetos-praga na cultura do arroz no Brasil. Pelotas, Embrapa Clima Temperado. 40p.

NOVARTIS. 1998. Thiamethoxam 250 WG. São Paulo, Novartis. 25p.

PAZINI, J.B.; BOTTA, R.A.; SILVA, F.F. 2012. Mortalidade de percevejo-do-colmo do arroz no preparo do solo para cultivo mínimo. Pesquisa Agropecuária Brasileira, Brasília, v.47, p.1022-1024.

RIGITANO, R.L.O; CARVALHO, G.A. 2001. Toxicologia e seletividade de inseticidas. Lavras: UFLA/FAEPE. 72p.

SANTOS, M.A.T.; AREAS, M.A.; REYES, F.G.R. 2007. Piretroides - uma visão geral. Alimentos e Nutrição, Araraquara, v.18, n.3, p.339-349.

SILVA, R.G.; CÂNDIDO, M.J.D.; NEIVA, J.N.M.; LÔBO, R.N.B. SILVA, D.S. 2007. Características estruturais do dossel de pastagens de capim-tanzânia mantidas sob três períodos de descanso com ovinos. Revista Brasileira de Zootecnia, Viçosa, v.36, n.5, p.1255-1265.

TEIXEIRA, I.; BOTTON,M.; LOECK,A.E. 2002. Avaliação de inseticidas visando ao controle de Eurhizococcus brasiliensis (Hempel) (Hemiptera: Margarodidae) em novos plantios de videira. Neotropical 
Entomology, Londrina, v.31, n.3, p.457461.

TORRES, F.Z.V.; RIGITANO, R.L.O. 2012.

Translocação do inseticida tiametoxam no floema de mamoneiras, utilizadas como plantas modelo. Pesticidas: Revista de Ecotoxicologia e Meio Ambiente, Curitiba, v.22, n.1, p.51-64.

Recebido em: $10 \backslash 11 \backslash 2013$ Aceito para publicação em:24\11\2013 